\title{
The adequacy of oxygenation in COPD patients undergoing long-term oxygen therapy assessed by pulse oximetry at home
}

\author{
P. Śliwiński, M. Łagosz, D. Górecka, J. Zieliński
}

\begin{abstract}
The adequacy of oxygenation in COPD patients undergoing long-term oxygen therapy assessed by pulse oximetry at home. P. Sliwiński, M. Lagosz, D. Górecka, J. Zieliński. CERS Journals Ltd 1994.

ABSTRACT: It is probable that some daily activities may cause marked falls in arterial oxygen saturation $\left(\mathrm{SaO}_{2}\right)$ in patients undergoing long-term oxygen therapy (LTOT), despite good oxygenation at rest.

We estimated the adequacy of LTOT in 34 randomly selected chronic obstructive pulmonary disease (COPD) patients at home by monitoring $\mathrm{SaO}_{2}$ continuously over $24 \mathrm{~h}$. The subjects were also asked to complete a questionnaire listing frequent daily activities.

Despite almost normal mean $\mathrm{SaO}_{2}(94 \%)$ at the beginning of recording $\left(\mathrm{O}_{2} 2 \mathrm{l} \cdot \mathrm{min}^{-1}\right.$, at rest) the subjects studied spent $6.9 \mathrm{~h}$ below an $\mathrm{SaO}_{2}$ of $90 \%$, with minimum $\mathrm{SaO}_{2}$ of $61 \%$. On average we observed 10 episodes of desaturation in each patient over $24 \mathrm{~h}$, both while breathing air and oxygen. The comparison of $\mathrm{SaO}_{2}$ recordings and questionnaires revealed the highest number of desaturations during sleep, followed by naps, watching the television, eating, washing and talking.

The oxygen flow rate prescribed, based on blood gas measurements at rest, did not protect $85 \%$ of the patients studied from deep falls in $\mathrm{SaO}_{2}$ during daily life. An increase of oxygen flow during some activities and during sleep is suggested.

Eur Respir J., 1994, 7, 274-278
\end{abstract}

Dept of Respiratory Medicine, Institute of Tuberculosis and Lung Diseases, Warsaw, Poland.

Correspondence: J. Zieliński

Dept of Respiratory Medicine

Institute of Tuberculosis and Lung Diseases ul. Plocka 26

01-138 Warsaw

Poland

Keywords: Chronic obstructive pulmonary disease

long-term oxygen therapy

oxygen saturation monitoring

pulse oximetry

Received: May 41993

Accepted after revision August 221993
The benefits of long-term oxygen therapy (LTOT) in patients with chronic obstructive pulmonary disease (COPD) have been reported by a number of investigators $[1,2]$. Since the 1980s, domiciliary oxygen therapy has been generally accepted as an important part of the routine treatment of COPD patients with chronic severe hypoxaemia. The main indication for LTOT is a low arterial oxygen tension $\left(\mathrm{PaO}_{2}\right)$, usually lower than $55 \mathrm{mmHg}(7.3$ $\mathrm{kPa})$. The prescribed oxygen flow should increase $\mathrm{PaO}_{2}$ to at least $65 \mathrm{mmHg}(8.7 \mathrm{kPa})$ [3]. The blood gas tensions used to qualify the patients for treatment are measured at rest. The oxygen flow rate is also adjusted in resting conditions.

In some cases, arterial oxygen saturation $\left(\mathrm{SaO}_{2}\right)$ during treadmill/cycle ergometer exercise or during sleep is also assessed [4], but rather to confirm the subject's eligibility for LTOT than to establish the adequate oxygen flow rate.

After the prescription of LTOT, the patients are followed in out-patient clinics or at home, and blood gas measurements are periodically performed at rest. Thus, there is no information about $\mathrm{SaO}_{2}$ in those patients during their daily activities at home. It is possible that some activities may cause important drops in $\mathrm{SaO}_{2}$, despite adequate oxygenation while resting.
The purpose of the present study was to estimate the adequacy of LTOT in COPD patients during their usual activities at home, by monitoring $\mathrm{SaO}_{2}$ continuously over $24 \mathrm{~h}$.

\section{Patients and methods}

Thirty four COPD patients, 20 males and 14 females, who were assessed and prescribed LTOT, were studied. They were randomly recruited from a group of 76 patients undergoing domiciliary oxygen therapy. They were at least 6 months on LTOT before the study started. The diagnosis of the disease was based on a history, clinical examination, chest X-ray, electrocardiography (ECG) and pulmonary function tests. The details of the qualification procedures for LTOT have been reported previously [5]. In short, patients had to present with chronic severe hypoxaemia $\left(\mathrm{PaO}_{2} \leq 55 \mathrm{mmHg}(7.3 \mathrm{kPa})\right)$ to qualify.

Special care was paid to exclude patients suspected of having obstructive sleep apnoea. All subjects completed a Marburg questionnaire and, in case of doubt, overnight pulse oximetry and snoring recordings were performed. 
All patients were prescribed supplemental oxygen at 2 $l \cdot \mathrm{min}^{-1}$ by nasal prongs, in order to increase $\mathrm{PaO}_{2}$ above $65 \mathrm{mmHg}(8.7 \mathrm{kPa})$ at rest. Oxygen was delivered by a Healthdyne BX-5000 oxygen concentrator. Each oxygen concentrator was tested for oxygen output before and after monitoring, to ensure that it produced a sufficient concentration of oxygen. In all oxygen concentrators the concentration of $\mathrm{O}_{2}$ in the gas was above $92 \%$ at a prescribed flow. Patients were asked to breathe oxygen as long as possible, but not less than $17 \mathrm{~h} \cdot \mathrm{day}^{-1}$, including the entire night.

To minimize the effect of limited activity of the patient due to usage of the oxygen concentrator, and therefore conceivably the degree of desaturation related to activity, the tubing connecting the concentrator and the patient was arranged in such a way that the patient could easily reach any point at home while breathing oxygen.

Arterial oxygen saturation recordings were continuously performed over $24 \mathrm{~h}$ by two pulse oximeters (Minolta Pulsox 7) using a finger sensor. The first oximeter was attached to the subject at 9 a.m. and replaced by the second at 9 p.m. To assure good quality of signal from the finger probe, great attention was paid to attaching it well to avoid change in position on the finger. Poor quality recordings due to movement of the probe were characterized by high frequency oscillations, which were easy to identify and delete from the record. We also introduced a quality index of the recording that estimated the percentage of total monitoring time, when the subject was correctly connected to the pulse oximeter.

The pulse oximeter attached to the patient could be powered either from a battery or an electrical outlet. This allowed the patient to perform outdoor activities, such as walking or shopping. The connection to the electrical outlet, mainly used in the home, was of sufficient length to ensure it did not limit the subject's activity. Patients were asked to spend a day of recording in their usual manner, and to complete a questionnaire covering $24 \mathrm{~h}$ divided into $15 \mathrm{~min}$ periods. The questionnaire was designed to quantify frequent activities which were important in the patient's daily life. It listed the following activities: washing, dressing, eating, housework, resting or having a nap, reading, watching television, listening to the radio, walking, talking, being angry or upset, experiencing chest pain, dyspnoea or cough, sleep, and breathing without oxygen. The comparison of $\mathrm{SaO}_{2}$ recordings and questionnaires allowed us to match the activities that caused a marked decrease in arterial oxygen saturation (fig. 1).

The oximeter signal was analysed by means of a computer and specially designed software. Analysis was performed separately for the $12 \mathrm{~h}$ periods, 9 a.m. to 9 p.m.
$\mathrm{SaO}_{2} \%$

9 a.m. to 9 p.m.

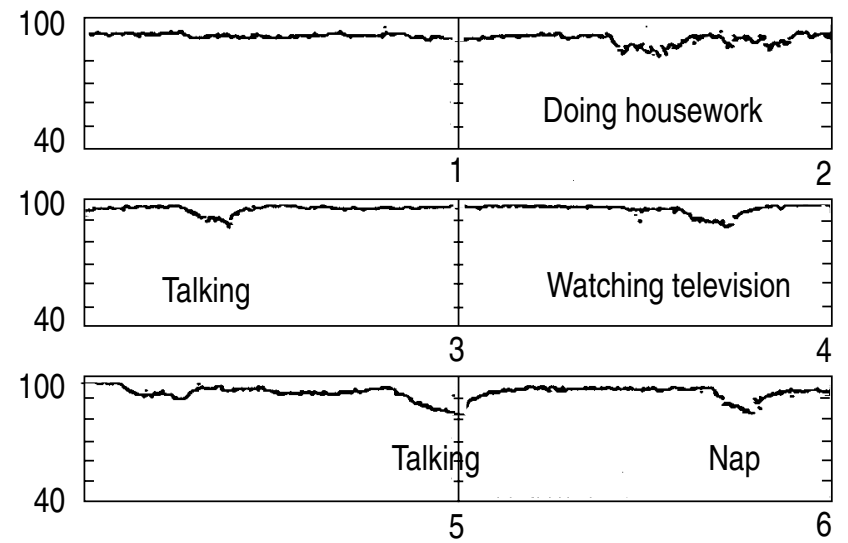

100

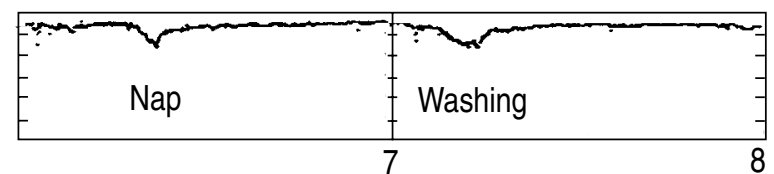

100

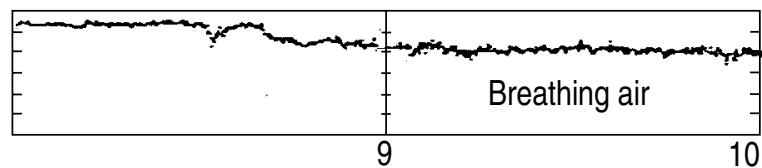

100

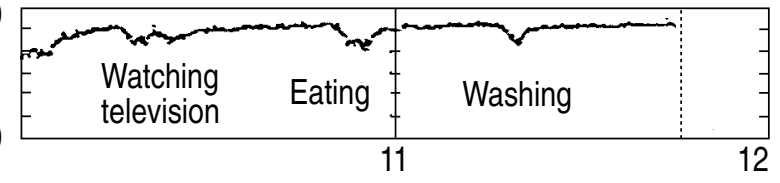

Time $\mathrm{h}$
$\mathrm{SaO}_{2} \%$

9 p.m. to 9 a.m.
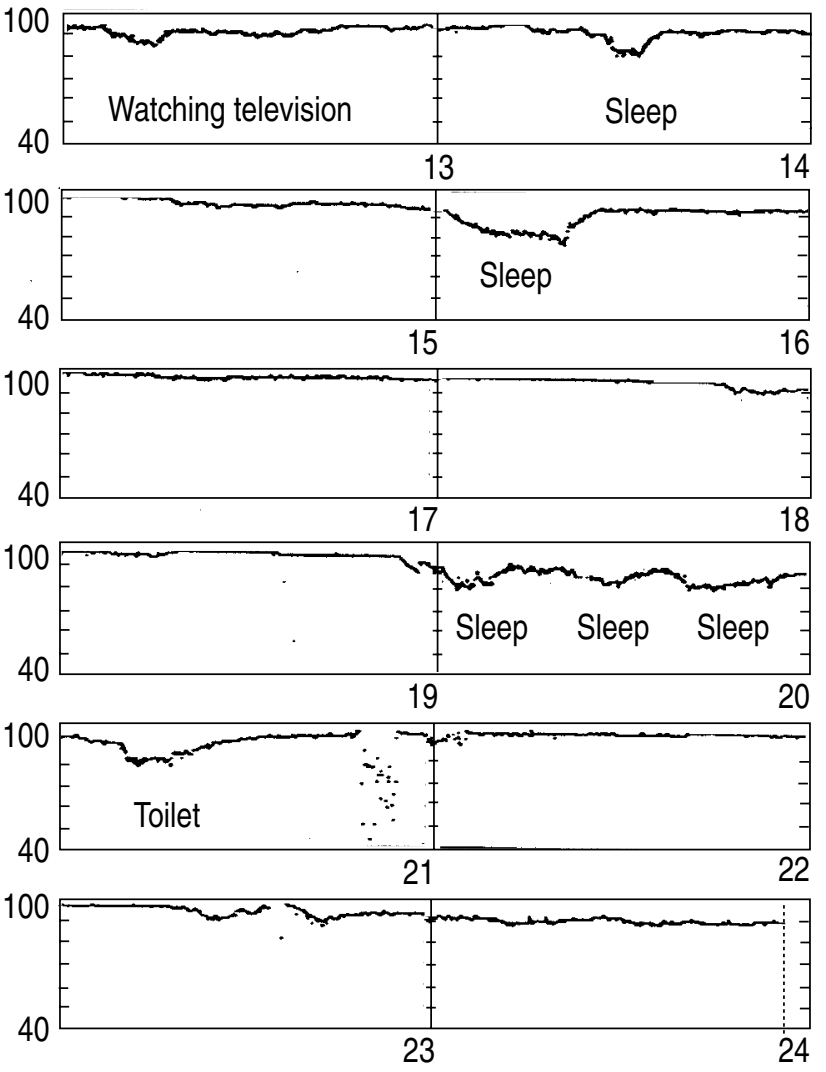

Time $\mathrm{h}$

Fig. 1. - Illustration of $24 \mathrm{~h}$ arterial oxygen saturation $\left(\mathrm{SaO}_{2}\right)$ recording in one representative patient. Falls in SaO ${ }_{2}$ during different activities are shown. 
("daytime") and 9 p.m. to 9 a.m. ("night"). $\mathrm{SaO}_{2}$ at the beginning of the study was determined from measurements taken during the first $30 \mathrm{~min}$, whilst the subject was breathing oxygen at rest. A desaturation period was defined as a drop of $\mathrm{SaO}_{2}$ below $90 \%$ for at least $5 \mathrm{~min}$. During the desaturation period, the nadir value of $\mathrm{SaO}_{2}$ had to fall to $85 \%$ or less at least once [6].

\section{Statistical analysis}

Differences in mean values were analysed by the Student's t-test for paired data. All reported values are mean \pm SD.

\section{Results}

Baseline characteristics of the 34 patients studied are presented in table 1. Fifteen of them presented with "pink puffer" and 19 with "blue bloated" clinical picture [7]. All subjects had severe airways obstruction, with accompanying blood gas abnormalities. $\mathrm{SaO}_{2}$ measurements at the beginning of recording, while the subjects were breathing oxygen at the prescribed flow rate, revealed adequate oxygenation in all patients (mean $94 \pm 1.8 \%$ ).

Mean oxygen breathing time of the patients studied on the day of investigation was $19.3 \mathrm{~h}$. This was longer than the average time on oxygen recorded over 1 month $(16.2 \mathrm{~h})$.

The quality index of the pulse oximeter recording estimating the percentage of total monitoring time when the subject was correctly connected to the probe, was $99 \%$, indicating that data removed from analysis had only a negligible impact on the overall result.

The results of pulse oximetry obtained during $12 \mathrm{~h}$ monitoring periods are shown in table 2. Mean and minimum $\mathrm{SaO}_{2}$ during both recording periods were almost at the same level, $92 \pm 3.2 \%$ versus $92 \pm 3.2 \%$ and $59 \pm 13.8 \%$ versus $62 \pm 15.4 \%$, respectively. Also, the total time of

Table 1. - Baseline characteristics of 34 COPD patients

\begin{tabular}{lc}
\hline \multicolumn{2}{l}{ Variable } \\
\hline Age yrs & \\
$\mathrm{FVC} l$ & $61 \pm 9$ \\
$\mathrm{FVC} \%$ pred & $2.25 \pm 0.9$ \\
$\mathrm{FEV}_{1} l$ & $55 \pm 16.6$ \\
$\mathrm{FEV}_{1} / \mathrm{FVC} \mathrm{\%}$ & $0.69 \pm 0.25$ \\
$\mathrm{PaO}_{2} \mathrm{mmHg}$ & $32 \pm 8.2$ \\
$\mathrm{PaCO}_{2} \mathrm{mmHg}$ & $52.4 \pm 6.6$ \\
$\mathrm{PreSaO}_{2} \%$ on $\mathrm{O}_{2}$ & $7.0 \pm 0.9$ \\
$\mathrm{Hct}^{2}$ & $48.7 \pm 7.3$ \\
& $6.5 \pm 1.0$ \\
& $94 \pm 1.8$ \\
\end{tabular}

Data are presented as mean \pm SD. COPD: chronic obstructive pulmonary disease; FVC: forced vital capacity; $\mathrm{FEV}_{1}$ : forced expiratory volume in one sec; $\mathrm{PaO}_{2}$ : arterial oxygen tension; $\mathrm{PaCO}_{2}$ : arterial carbon dioxide tension; $\mathrm{PreSaO}_{2}$ : arterial oxygen saturation during the first 30 min of recording; Hct: haematocrit.
Table 2. - Results of $24 \mathrm{~h}$ pulse oximetry at home

\begin{tabular}{lcc}
\hline Variable & 9 a.m. to 9 p.m. & 9 p.m. to 9 a.m. \\
\hline meanSaO $_{2} \%$ & $92 \pm 3.2$ & $92 \pm 3.2$ \\
$\mathrm{minSaO}_{2} \%$ & $59 \pm 13.8$ & $62 \pm 15.4$ \\
$\mathrm{SaO}_{2}<90 \% \%$ & $30 \pm 26.7$ & $28 \pm 27.3$ \\
$\mathrm{SaO}_{2}<85 \% \%$ & $10 \pm 16.1$ & $9.3 \pm 12.3$ \\
$\mathrm{SaO}_{2}<80 \% \%$ & $2.8 \pm 5.8$ & $2.9 \pm 6.7$ \\
$\mathrm{SaO}_{2}<75 \% \%$ & $1.0 \pm 2.8$ & $1.1 \pm 3.1$ \\
$\mathrm{Use}_{2} \% \mathrm{O}_{2} \mathrm{~h}$ & $8.7 \pm 3.2$ & $10.6 \pm 2.0$
\end{tabular}

Data are presented as mean $\pm \mathrm{SD}$. $\mathrm{SaO}_{2}$ : arterial oxygen saturation. $\mathrm{minSaO}_{2}$ : minimum $\mathrm{SaO}_{2} ; \mathrm{SaO}_{2}<90 \%,<85 \%,<80 \%,<75 \%$ : time spent with $\mathrm{SaO}_{2}$ below $90,85,80$ and $75 \%$, respectively, (in percentage of the total recording time).

the study that the patients spent below an $\mathrm{SaO}_{2}$ of 90,85 , 80 and $75 \%$ did not significantly differ between daytime and night. The desaturation periods while breathing oxygen lasted $63 \mathrm{~min}$ during daytime recording and $84 \mathrm{~min}$ during night (NS).

In total, 301 episodes of desaturation were observed (on average 10 episodes in each subject over $24 \mathrm{~h}$ ), 169 between 9 a.m. and 9 p.m. and 132 between 9 p.m. and 9 a.m. (table 3). One hundred and eighteen desaturation episodes occurred when subjects were breathing air, and 183 when breathing oxygen. The highest number of desaturation periods was observed during sleep (64), followed by having a nap (43), watching the television (38), eating (30), washing (29), and talking (29).

The majority of desaturation periods during sleep was observed in "blue and bloated" patients (47 out of 64). Seventy three out of 135 hypoxic episodes in these subjects, that occurred during other daly activities, were noted while breathing oxygen. In "pink puffers", 50 out of 102 desaturation periods during daily activities were observed when breathing oxygen (table 4).

In five subjects (all "pink puffers"), episodes of desaturation were not observed. In another two patients, such episodes occurred only while breathing air.

Patients breathed oxygen for less hours during the daytime than at night; 8.7 versus $10.6 \mathrm{~h}$, respectively, $(\mathrm{p}=0.002)$.

Table 3. - Number of desaturation episodes observed in the patients studied during various activities

\begin{tabular}{lrrrrr}
\hline \multirow{2}{*}{ Activity } & \multicolumn{2}{c}{9 a.m. to 9} & p.m. & & \multicolumn{2}{c}{ p.m. to 9 a.m. } \\
\cline { 2 - 3 } \cline { 5 - 6 } & Oxygen & Air & & Oxygen & Air \\
\hline Time h & 8.7 & 3.3 & & 10.6 & 1.4 \\
& & & & & \\
Housework & 1 & 11 & & 0 & 0 \\
Dressing & 0 & 3 & & 3 & 7 \\
Dyspnoea or cough & 5 & 2 & & 2 & 0 \\
Eating & 10 & 10 & & 5 & 5 \\
Nap or rest & 28 & 6 & & 3 & 6 \\
Reading & 8 & 9 & & 3 & 2 \\
Sleep & 0 & 0 & & 60 & 4 \\
Talking & 13 & 11 & & 0 & 5 \\
Walking & 2 & 7 & & 0 & 3 \\
Washing & 10 & 5 & & 5 & 9 \\
Watching television & 22 & 6 & & 3 & 7 \\
\hline
\end{tabular}


Table 4. - Number of desaturation episodes in "pink puffers" and "blue bloaters" during sleep and daytime

\begin{tabular}{lcccccc}
\hline \multirow{2}{*}{ Patients } & & \multicolumn{3}{c}{ Sleep } & & \multicolumn{2}{c}{ Other activities } \\
\cline { 3 - 4 } \cline { 7 - 8 } & $\mathrm{n}$ & Oxygen & Air & & Oxygen & Air \\
\hline Pink puffers & 15 & 17 & 0 & & 50 & 52 \\
Blue bloaters & 19 & 43 & 4 & & 73 & 62 \\
\hline
\end{tabular}

\section{Discussion}

The main goal of this study was to assess the adequacy of oxygenation in COPD patients undergoing LTOT during their usual activities at home during $24 \mathrm{~h}$.

The surprisingly good quality of pulse oximetry recording was due to the special care paid to optimal attachment of the probe, allowing virtually no change in its position on the finger. Also, the majority of the recordings were obtained when patients were at home and the pulse oximeter was powered from the electrical outlet. This prevented a deterioration of the quality of the signal that we observed sometimes if using a fading battery.

The subjects studied showed a satisfactory $\mathrm{SaO}_{2}(94 \%)$ at the beginning of recordings, whilst breathing oxygen at rest. Also, the mean $\mathrm{SaO}_{2}(92 \%)$ measured over $24 \mathrm{~h}$ seemed adequate. Nevertheless, a detailed analysis of oxygenation revealed a relatively low minimum value of $\mathrm{SaO}_{2}(61 \%)$. The total time spent below a saturation of $90 \%(6.9 \mathrm{~h})$ was much longer than the total time during room air breathing $(4.7 \mathrm{~h})$. This means that, on average, our subjects spent $2.2 \mathrm{~h}$ a day with a saturation below $90 \%$, despite breathing oxygen. These desaturations were observed during daytime and at night, while breathing air or oxygen. Thus, an almost normal level of $\mathrm{SaO}_{2}$ determined during a short period of time while the patients were awake and at rest did not guarantee adequate oxygenation in $85 \%$ of our subjects during $24 \mathrm{~h}$ monitoring.

The question arises as to whether the observed desaturation dips might have been harmful for the patients studied. It has been reported that the extent of nocturnal hypoxaemia is not clinically important [8]. Also, the improvement of exercise tolerance by oxygen breathing may be questionable [9]. On the other hand, there is evidence that interruption of oxygen breathing in COPD patients treated with LTOT results in an immediate increase in pulmonary artery mean pressure $\overline{(\mathrm{PAP})}$ [10]. Transient nocturnal oxyhaemoglobin desaturation during sleep, accompanied by aggravation of pre-existing pulmonary hypertension, has been commonly observed in COPD patients $[11,12]$. Those two findings, together with the well-known correlation between the level of pulmonary hypertension and survival in COPD patients [13, 14], suggest that good oxygenation of subjects undergoing LTOT should be maintained continuously.

There is another occasion when such patients may become more hypoxaemic in stable periods of the disease. It has been shown that even low grade exercise may significantly decrease oxygen saturation and increase $\overline{\mathrm{PAP}}[15,16]$.
Administration of supplemental oxygen may improve pulmonary circulation by lowering existing pulmonary hypertension as well as by eliminating increases in PAP associated with hypoxaemic episodes [17]. Similarly, supplemental oxygen during exercise protects patients from dangerous desaturations, and may improve exercise performance [18].

The desaturation periods observed during air breathing might have been eliminated by encouraging patients to use oxygen continuously. This is, however, very difficult to achieve in reality, especially for a subject who wants to continue outdoor activities. It seems that hypoxaemic episodes noticed during an oxygen breathing period could have been more easily corrected. The increase of oxygen flow rate above the resting level during some daily activities and during sleep might have improved oxygenation in most cases. The additional amount of oxygen should be established empirically, taking into account the level of $\mathrm{PaCO}_{2}$ that may limit oxygen flow rate.

The influence of sleep on duration of hypoxaemic episodes can be explained by a variety of factors, such as the aggravation of mismatched ventilation and perfusion [19], or the rapid eye movement (REM) sleep effect [20]. We cannot exclude the possibility that some patients, having misplaced their prongs, breathed oxygen only for some periods during sleep. Several studies have shown that such hypoxaemic episodes are associated with severe cardiac arrhythmias $[21,22]$, and increases in PAP $[11$, 12]. Furthermore, FLETCHER et al. [23] found significantly better survival in COPD patients who did not desaturate at night compared to those who did. We therefore speculate that the reason for a higher mortality in desaturating patients may be, at least partly, due to longer periods of hypoxaemia at night than in the daytime.

The majority of hypoxaemic episodes during sleep (73\%) were noticed in "blue and bloated" patients, although this was only $26 \%$ of their total desaturation episodes (table 4). "Pink puffers" suffered mostly from hypoxaemic periods during the daytime (they made up $86 \%$ of total desaturations in this group). This is consistent with other studies reporting that nocturnal hypoxaemic episodes occurred more often in "blue bloaters" than in "pink puffers" [20].

It may be surprising that $61 \%$ of desaturation episodes occurred when patients were breathing oxygen. These episodes, however, were recorded during a significantly longer time $(19.3 \mathrm{~h})$ than those on air $(4.7 \mathrm{~h})$. Interestingly, $50 \%$ of hypoxaemic periods observed when breathing oxygen occurred during naps or sleep. These two conditions were accompanied by falls in $\mathrm{SaO}_{2}$ more frequently than others. A surprisingly high number of desaturations was noticed while watching the television. Presumably some of these were also caused by naps.

Although oxygen therapy at the constant flow rate did not completely prevent our subjects from severe desaturations, its efficacy still seems to be high. On average, there was one desaturation episode every $3.06 \mathrm{~h}$ when breathing oxygen and one every $1.15 \mathrm{~h}$ when breathing air.

We conclude that the prescription of oxygen flow rate based on awake, resting blood gas measurements does 
not guarantee adequate oxygenation of COPD patients during their daily life. The elevation of oxygen flow rate by an empirically established amount (presumably by $1-1.5 l \cdot \mathrm{min}^{-1}$ ) before some daily activities and before sleep, to prevent falls in $\mathrm{SaO}_{2}$, is suggested. However, a high level of $\mathrm{PaCO}_{2}$ and the type of oxygen source may be a useful tool to detect inadequate oxygenation in patients despite LTOT.

Acknowledgements: The authors wish to thank L. Tylka, for performing all pulse oximetry recordings and for her devotion to patients on LTOT.

\section{References}

1. Report of the Medical Research Council Working Party. Long-term domiciliary oxygen therapy in chronic hypoxic cor pulmonale complicating chronic bronchitis and emphysema. Lancet 1981; 1: 681-685.

2. Nocturnal Oxygen Therapy Trial Group. Continuous or nocturnal oxygen therapy in hypoxemic chronic obstructive lung disease. Ann Intern Med 1980; 93: 391-398.

3. Zieliński J, Śliwiński P. Indications for and methods of long-term oxygen therapy (LTOT). Eur Respir Rev 1991; 1: 536-540.

4. Śliwiński P, Skwarski K, Hawryłkiewicz I, Zieliński J. Pulse oximetry on exercise and at night in COPD patients qualified for LTOT. Eur Respir J 1989; 2 (Suppl. 5): $364 s$.

5. Śliwiński P, Hawryłkiewicz I, Górecka D, Zieliński J. The acute effect of oxygen on pulmonary arterial pressure does not predict survival on long-term oxygen therapy in COPD patients. Am Rev Respir Dis 1992; 146: 665-669.

6. Fletcher EC, Miller J, Divine GW, Fletcher JC, Miller T. Nocturnal oxyhemoglobin desaturation in COPD patients with arterial oxygen tensions above $60 \mathrm{mmHg}$. Chest 1987; 92: 604-608.

7. Burrows B, Kettel LH, Niden AH, Rabinowitz M, Diener CF. Patterns of cardiovascular dysfunction in chronic obstructive lung disease. N Engl J Med 1972; 286: 912-918.

8. Connaughton JJ, Catterall JR, Elton RA, Stradling JR, Douglas NJ. Do sleep studies contribute to the management of patients with severe chronic obstructive pulmonary disease? Am Rev Respir Dis 1988; 138: 341-344.

9. Skorodin M, Barner K, Belingon E. Acutely administered and long-term $\mathrm{O}_{2}$ supplementation does not improve exercise tolerance or reduce dyspnea in pink puffers. $A m$ Rev Respir Dis 1989; 139 (Suppl. 4): p. 2, A330.
10. Selinger SR, Kennedy TP, Buescher P, et al. Effects of removing oxygen from patients with chronic obstructive pulmonary disease. Am Rev Respir Dis 1987; 136: 85-91.

11. Coccagna G, Lugaresi E. Arterial blood gases and pulmonary and systemic arterial pressure during sleep in chronic obstructive pulmonary disease. Sleep 1978; 1: 117-124.

12. Fletcher EC, Luckett RA, Miller T, Costarangos C, Kutka N, Fletcher JG. Pulmonary vascular hemodynamics in chronic lung disease patients with and without oxyhemoglobin desaturation during sleep. Chest 1989; 95: 157-166.

13. Weitzenblum E, Hirth C, Ducolone A, Mirhom R, Rasaholinjamahary J, Ehrhart M. Prognostic value of pulmonary artery pressure in chronic obstructive pulmonary disease. Thorax 1981; 36: 752-758.

14. Finlay M, Middleton HC, Peake MD, Howard P. Cardiac output, pulmonary hypertension, hypoxaemia and survival in patients with chronic obstructive airway disease. Eur J Respir Dis 1983; 64: 252-263.

15. Dantzker DR, D'Alonzo GE. The effect of exercise on pulmonary gas exchange in patients with severe chronic obstructive pulmonary disease. Am Rev Respir Dis 1986; 134: 1135-1139.

16. Timms RM, Khaja FU, Williams GW. Hemodynamic response to oxygen therapy in chronic obstructive pulmonary disease. Ann Intern Med 1985; 102: 29-36.

17. Fletcher EC, Levin DC. Cardiopulmonary hemodynamics during sleep in subjects with chronic obstructive pulmonary disease. The effect of short- and long-term oxygen. Chest 1984; 85: 6-14.

18. Davidson AC, Leach R, George RJD, Geddes DM. Supplemental oxygen and exercise ability in chronic obstructive airways disease Thorax 1988; 43: 965-971.

19. Catterall JR, Calverley PMA, McNee W, et al. Mechanism of transient nocturnal hypoxemia in hypoxic chronic bronchitis and emphysema. J Appl Physiol 1985; 59: 1698-1703.

20. Douglas NJ, Calverley PMA, Leggett RJE, Brash HM, Flenley DC, Brezinova V. Transient hypoxemia during sleep in chronic bronchitis and emphysema. Lancet 1979; 1: $1-4$.

21. Flick MR, Block AJ. Nocturnal vs diurnal cardiac arrhythmias in patients with chronic obstructive pulmonary disease. Chest 1979; 75: 8-11.

22. Skwarski K, Śliwiński P, Zieliński J. Correlation between nocturnal hypoxaemia and cardiac arrhythmias in stable COPD patients. Bull Eur Physiopathol Respir 1987; 23 (Suppl. 12): 423s.

23. Fletcher EC, Donner CF, Midgren B, et al. Survival in COPD patients with a daytime $\mathrm{PaO}_{2}$ greater than $60 \mathrm{mmHg}$ with and without nocturnal oxyhemoglobin desaturation. Chest 1992; 101: 649-655. 